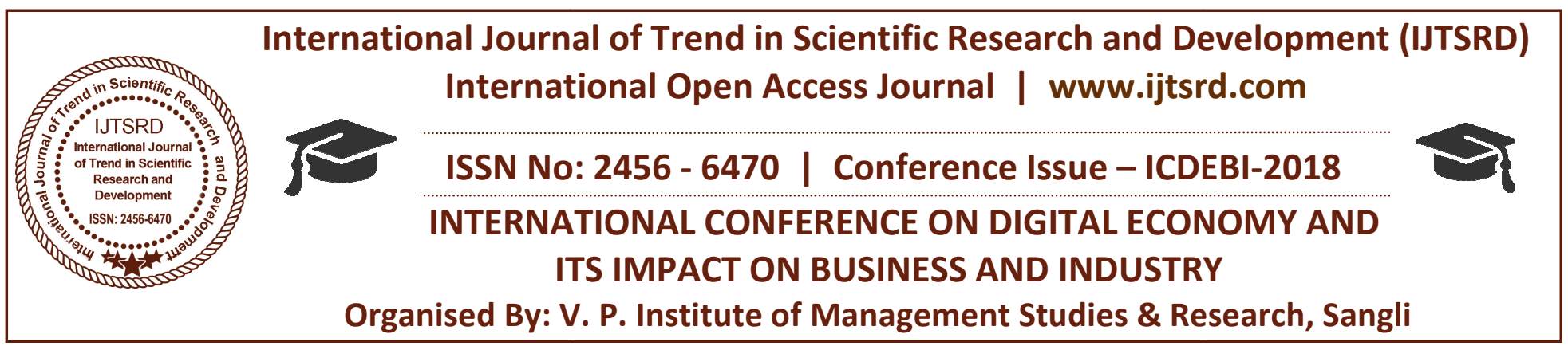

\title{
Digitlal Economy and Digital Divide: Balancing for Growth
}

\author{
Dr. T. V. G. Sarma \\ Associate Professor \& Head Department of Economics, \\ Chhatrapati Shahu Institute of Business Education \& Research, Kolhapur, Maharashtra, India
}

\begin{abstract}
The paper examines the issue of the "digital divide" in all societies. It becomes more serious when the societies are already imbalanced with regard to economic and social structures. The people with access are becoming richer while the poor are being left behind aggravating the divide further. In this information era where earning is a function of learning the digital divide will keep a vast section of the society in dark age due to lack of access to information. This is the exact issue of digital divide. This divide is not going to reduce unless there is a conscious effort from the policy makers and planners.. As it is stated correcting the digital divide, will provide the greatest opportunity for people to come out of poverty and ignorance. But the study shows the gap is continuously expanding throwing a big challenge to the planners to balance the twin objective of growth in digitization and reduction in the digital divide.
\end{abstract}

\section{INTRODUCTION}

The Digital Economy world over is creating fastest generation of wealth that was never experienced in the history of mankind. The growth is the result of the belief that business and society will be guided by technology and the world of computers in the coming years. This presumption is surprising as vast majority of people still do not have access to basic technological knowledge and resources. Except of few pockets of cities world over there is lack of education and teaching resources for making this dream a reality.

Recognising this gap the individual and government organisations are offering outreach programs in the fundamentals of the emerging technologies. They are

emphasizing the importance of technological knowledge for people from all walks of life. In other words these individual and organizational initiatives are attempting to reduce the 'Digital Divide' being experienced among all age groups in the society.

\section{DEFINITION OF DIGITAL DIVIDE:}

In the recent years the dependence of people on computers has increased for performing all types of tasks. The ability of a person to access the computers and technological gadgets has increased his knowledge about the social and economic events happening in different countries. But everyone in the society is not able to access this technology with ease. The concept of digital divide refers to the gap between the people who are able to access the technology and the people who are not able to access it for variety of reasons. The people falling under the category of less or no access at all are the poor, handicapped, rural and senior citizens.

\section{REASONS FOR DIGITAL DIVIDE:}

Along with the fast growth of technology there is equivalent or still faster growth of the digital divide. A section of the society that is already connected that includes the rich and educated, are adopting new technologies very fast and becoming more connected. On the other hand there is the other section which has less access to internet and computers are lagging far behind. Number of studies have also highlighted that this divide is becoming wider across the various economic and social classes.

\section{LEVEL OF EDUCATION:}

The gaps in the levels of education appear to be widening the digital divide. People with high level 
of education are more likely to access the internet than people with lower levels of education. Research studies have also determined that people with graduate degrees are 10 times more likely to use technology than those with only high school education. Over the years the digital divide between these two groups of educated class increased from $8 \%$ to $25 \%$

\section{$>$ INCOME EARNINGS}

The income earnings is also related to the digital divide. The higher the income earnings of a family it is more likely to adapt to the new technologies. While the lower income earnings are less likely to go for these advancements in these areas. Poor neighbourhoods do not have the infrastructure of the rich areas. The information technology facilities are available in rich areas. The companies dealing in these equipments get attracted to the rich areas. Poverty makes it less attractive for companies to venture for the poor thereby making the divide still wider.

\section{$>$ VARIED SOCIAL CLASS}

Digital divide is also observed across different social class. The progressive class tend view the use of technology as an addition to knowledge and the path for their individual and family progress. While people for the lower class tend to view the investment in computers as a luxury expenditure. The computers isolate the individuals from family life. As a result the gap in internet usage too between these two broad social classes widens creating a bigger digital divide.

\section{POSSIBLE SOLUTIONS:}

The issue of digital divide is a matter of serious concern. Though it is a serious problem it is not unsolvable. If some of the following measures are undertaken the magnitude of the problem can surely be reduced.

\section{> INCREASING COMPETITION}

One of the reasons for the relatively poor to not access the computers are the high cost. The computers market can be considered to be monopolistic where few producers dominate the markets. The Government through policy measures can encourage new entrepreneurs so that the average price reduces. More number of players should also be encouraged to provide the services in the rural areas to reduce the divide.

\section{$>$ PUBLIC ACCESS CENTERS}

In rural and semi-urban areas where the due to variety of reasons individuals cannot purchase the computers the Government should invest in creating computer centers accessible at different public places. It will be a convenient and affordable for the poor, unemployed and people from lower classes to use it for their individual and societal benefit.

\section{CREATING A POOL OF TRAINERS}

Number of people do not immediately adapt to the new technologies either due to lack of knowledge or due to the fear of using them due to ignorance. This negative tendency causing the digital divide to increase can be corrected to a large extent if we create a pool of trainers in new technologies in all the areas. They will encourage the poor, unemployed and socially disadvantaged groups to use the technologies and guide them whenever they struck up in their use.

\section{CHANGE IN PERCEPTION}

As stated earlier one of the factors contributing for the digital divide is the perception of the people towards the technology products including the computers as luxury items. Only when this wrong notion is corrected the process of reducing the divide will be initiated. People should start viewing them as necessities. They should understand and accept the power of technology as tools for growth.

\section{INVOLVING CIVIL SOCIETY GROUPS}

The reach of civil society especially the nongovernment organizations is a well known fact. The ability of the group to reach far and wide can be harnessed to spread the awareness about the technology and computers. Their skill to convince the rural poor will be of immense use for bridging the digital divide.

\section{HARNESSING THE C.S.R. RESOURCES}

In many developing societies the high cost of the information technology infrastructure contributes for increasing the digital divide. The private corporate can be encouraged to invest and create the technology infrastructure in schools especially in the rural areas as a part of their C.S.R initiatives. The success of the private intervention in other areas will also give positive result in reducing the digital divide.

\section{SUMMARY}

The paper reveals that the issue of the "digital divide" is a matter of concern for all societies. It becomes more serious when the societies are already imbalanced with regard to economic and social structures. The people with access are becoming 
richer while the poor are being left behind aggravating the divide further. In this information era where earning is a function of learning the digital divide will keep a vast section of the society in dark age due to lack of access to information. This is the exact issue of digital divide. This divide is not going to reduce unless there is a conscious effort from the policy makers and planners. From the analysis it is clear that the main cause for digital divide is not the cost but the technological illiteracy among the people. The absolute level of illiteracy makes the promotion of technological illiteracy still more difficult. As it is stated correcting the digital divide, will provide the greatest opportunity for people to come out of poverty and ignorance. But as the data in shows the gap is continuously expanding throwing a big challenge to the planners to balance the twin objective of growth in digitization and reduction in the digital divide.

\section{REFERENCES:}

1. Mark Albala (2017): Thriving with information in the digital economy, Covenant Books Inc., U.S.A

2. Don Tapscott and Rod McQueen (2017): The digital economy: Promise and peril in the age of a networked intelligence, McGraw Hill Publications, U.S.A

3. Mark Bauerlein (2011): Digital Divide: The arguments for and against Facebook, Google, Texting, and the age of Social networking, Penguin Books, U.S.A

4. Neha Pathakji (2018): Corporations and Disability Rights: Bridging the Digital Divide, Oxford University Press, New Delhi

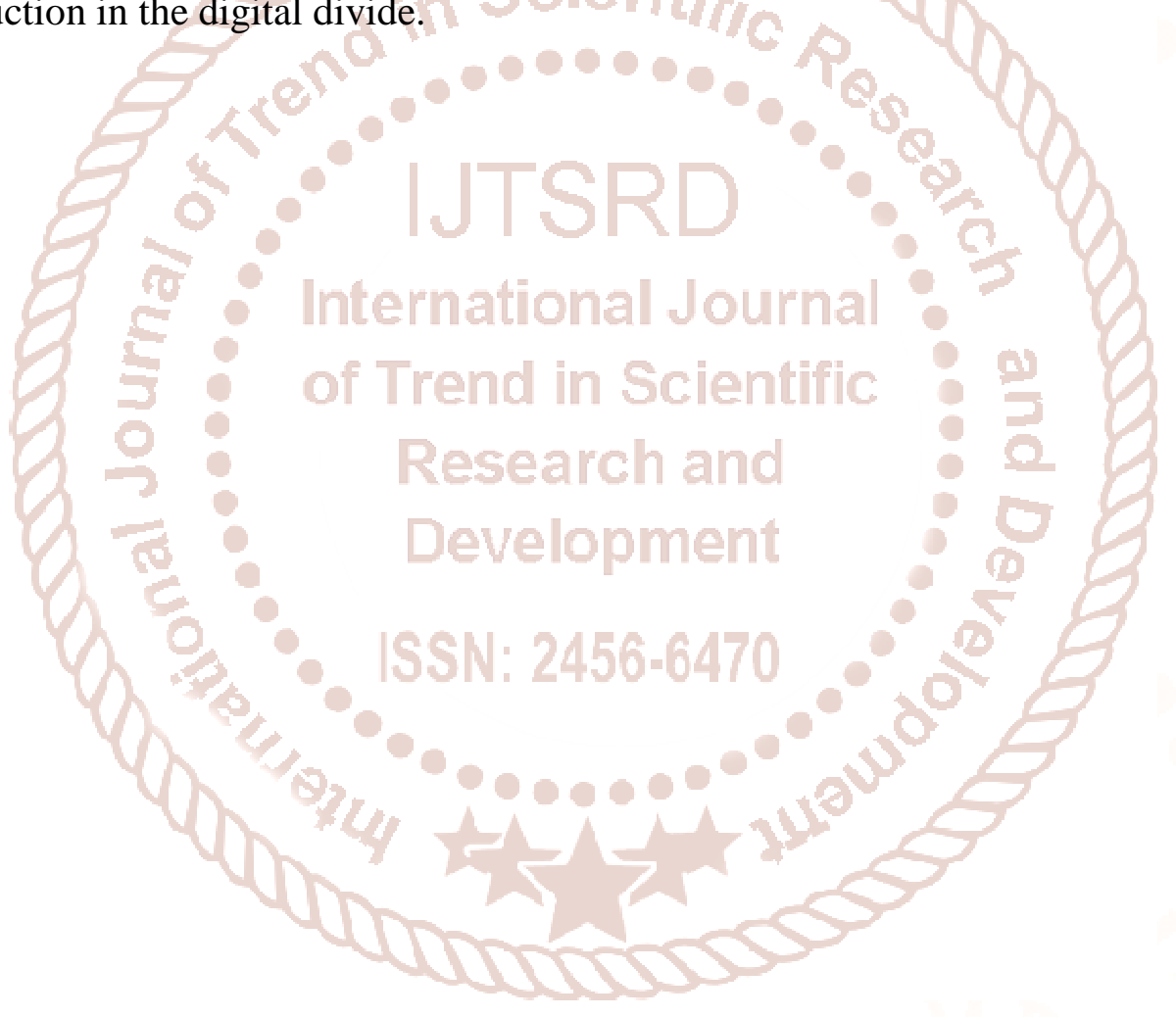

